Int. J. Electrochem. Sci., 11 (2016) 4410 - 4426

\title{
Electrode Material Properties and Modelling of 1-Methyl-3- octylimmidazolium bis(trifluoromethylsulfonyl)imide Ionic Liquid/ Paraffin Carbon Pastes
}

\author{
Tesfaye T. Waryo*, Sibusiso Qwesha, Priscilla G. Baker, Emmanuel I. Iwuoha \\ Department of Chemistry, University of the Western Cape, Bellville 7535, South Africa \\ "E-mail: twaryo@uwc.ac.za
}

doi: $10.20964 / 2016.06 .63$

Received: 21 December 2015 / Accepted: 23 March 2016 / Published: 4 May 2016

\begin{abstract}
A comparative study of the electrode properties of carbon pastes (CPs) composed of micro-particulate graphite powder and (1) 1-methyl-3-octylimmidazolium bis(trifluoromethylsulfonyl)imide ionic liquid (IL) only (ILCP), (2) 1:1 v/v IL/ paraffin (ILPCP), and (3) paraffin only (PCP) as binder liquids was carried out with cyclic voltammetry (CV) and impedance spectroscopy (EIS). ATR-FTIR spectra and scanning electron micrographs respectively revealed that most of the graphite particles were covered with the binder molecules, and that the IL resulted in more efficient binding of particles and formation of more compact pastes than did the paraffin. In the former case the particles appeared to have been transformed into thinner sheets (flakes), i.e. fewer of graphene layers, understood as being caused by IL-enhanced exfoliation of graphene. ILCP's intrinsic capacitive current density $\left.(\sim 2.5 \mathrm{~mA} \mathrm{~cm})^{-2}\right)$ was 100 -folds higher than that of PCP. The potential window was $2.5 \mathrm{~V}$ wide for ILCP and $2.2 \mathrm{~V}$ for ILPCP's. According to the EIS data, two conductive phases existed in ILPCP; ILCP was the least ohmic resistive paste, and that a diffusional capacitive process was involved in both. Based on the CV of $\left[\mathrm{Fe}(\mathrm{CN})_{6}\right]^{3-14}\left(E^{\circ \prime} \approx 0.200 \mathrm{~V}\right)$, the ILCP exhibited the highest peak currents and the highest effective electrochemical area to geometric area ratio $\left(A_{e f f} / A_{\text {geom }}\right)$, and the PCP the lowest. However, the $k^{o}$ determined by this method did not vary significantly with the paste composition. Thus, the presumed exfoliation of graphene only increased the $A_{\text {eff. }}$. The CPs are also compared with Pt and C electrodes.
\end{abstract}

Keywords: Ionic liquid, 1-methyl-3-octylimidazolium bis(trifluoromethyl)sulfonyl imide, graphite, carbon paste electrode

\section{$\underline{\text { FULL TEXT }}$}

(C) 2016 The Authors. Published by ESG (www.electrochemsci.org). This article is an open access article distributed under the terms and conditions of the Creative Commons Attribution license (http://creativecommons.org/licenses/by/4.0/). 